\title{
Cognitive behavioural therapy reduced cocaine abuse compared with 12 step facilitation
}

\author{
Maude-Griffin PM, Hohenstein JM, Humfleet GL, et al. Superior efficacy of cognitive-behavioral therapy for urban crack cocaine \\ abusers: main and matching effects. J Consult Clin Psychol 1998 Oct;66:832-7.
}

\section{Question}

Is cognitive behavioural therapy (CBT) more effective than 12 step facilitation (12SF) for reducing cocaine abuse in adults?

\section{Design}

Randomised controlled trial with 26 weeks follow up.

\section{Setting}

3 programmes of the Veterans Affairs Medical Center in San Francisco, California, USA.

\section{Participants}

128 adults (98\% men, 80\% African-American) who met DSMIII- $R$ criteria for cocaine abuse (mean duration of cocaine use 19 y). Exclusion criteria included opioid dependence, diagnosis of schizophrenia, or contraindications to outpatient treatment. Follow up was $84 \%$ at 26 weeks.

\section{Intervention}

Participants were allocated to CBT $(\mathrm{n}=59)$ or $12 \mathrm{SF}(\mathrm{n}=69)$, and they all received 3 group therapy sessions and 1 individual counselling session each week for 12 weeks. In 12SF, participants were introduced to the 12 steps of Alcoholics Anonymous and Cocaine Anonymous and were encouraged to do the first 4 steps and attend 12 step meetings in the community. CBT emphasised changing thoughts and behaviour to prevent relapses and increase social support. Participants in the CBT group were also encouraged to attend a cognitively based self help group.

\section{Main outcome measures}

4 consecutive weeks of abstinence during 12 weeks of treatment and rates of abstinence at 4, 8, 12, and 26 weeks. Abstinence was defined as no use of cocaine in the previous 30 days and a cocaine free urine sample. Patients were also assessed at baseline for drug use severity (Addiction Severity Index), history of major depressive disorder (Diagnostic Interview Schedule), abstract reasoning (subscale of the Shipley Institute of Living Scale), religious beliefs (Intrinsic Religious Motivation Scale), and belief in a disease model (Understanding of Alcoholism Scale).

\section{Main results}

More participants in CBT achieved 4 weeks of abstinence from cocaine than did those in 12SF $(p=0.04)$ (table). Participants in CBT were also more likely to be abstinent at each of the assessment points than were those in $12 \mathrm{SF}(\mathrm{p}=0.01)$. Among patients with major depressive disorder, CBT led to greater rates of 4 week abstinence than did 12SF (odds ratio [OR] 8.8, 95\% CI 1.6 to 47.5). Participants in the CBT group who had high abstract reasoning scores were more likely to achieve 4 weeks of abstinence than were those with low abstract reasoning scores (OR 4.5, CI 0.9 to 23.0). African-American participants in the 12SF group were more likely to be abstinent if they reported high levels of religious beliefs. Drug use severity and belief in a disease model were not associated with treatment outcomes.

\section{Conclusion}

Patients who were dependent on cocaine were more likely to be abstinent after cognitive behavioural therapy than after 12 step facilitation.

Cognitive behavioural therapy $v 12$ step facilitation in cocaine abuse

\begin{tabular}{lllll}
\hline Outcome at 26 weeks & $\begin{array}{l}\text { Adjusted } \\
\text { EER }\end{array}$ & $\begin{array}{l}\text { Control } \\
\text { rate }\end{array}$ & RBI (95\% CI) & NNT (CI) \\
\hline Abstinent for 4 weeks & $54 \%$ & $32 \%$ & $69 \%(4$ to 130$)$ & 5 (3 to 79)
\end{tabular}

*Abbreviations defined in glossary; EER, RBI, NNT, and CI calculated from adjusted odds ratio in article.

Sources of funding:Department of Veterans Affairs Health Services Research and Development Merit Review and the National Institute on Drug Abuse.

For correspondence:Dr S M Hall, Department of Psychiatry, University of California, 401 Parnassus (0984-F), San Francisco, CA 94143-0984, USA. Fax +1 4154767677

\section{Commentary}

Several elements of this important, well designed, clinical trial by Maude-Griffin $e t$ $a l$ are noteworthy from a clinical perspective. Firstly, the results provide important evidence to support the use of cognitivebehavioural interventions in cocaine treatment. As the authors note, previous research has produced mixed results; some studies have found behavioural interventions to be no more effective than no treatment. These studies, however, are not well designed investigations of theoretically based, well documented, valid, and replicable interventions such as this study. Secondly, the effectiveness of 12 step programmes for drug treatment has been questioned because correlations between attendance and abstinence do not necessarily imply a causal connection between the two. ${ }^{1}$ This study shows that patients randomly assigned to such programmes are less likely to abstain from drug use than patients randomly assigned to a cognitive behavioural intervention. Thirdly, this study shows that no single behavioural intervention is likely to meet the needs of all patients. The finding of important patient treatment interactions (ie, history of depression and amount of abstract reasoning) in a patient sample that is predominantly African-American, male, and homeless, suggests that the matching of treatment characteristics to patient characteristics by clinicians is vital to the success of any drug treatment programme. An alternative or adjunct to such matching is to combine various treatment modalities into one comprehensive programme, a technique that has been found to be more effective in treating drug abuse than single treatment modalities. ${ }^{2}$ Finally, as the authors observe, treatment retention remains a critical issue. Participants in this study attended an average of 14 out of 36 possible group therapy sessions and 5 out of 12 possible individual therapy sessions. This suggests that even the most clinically effective therapies are likely to have little effect unless greater efforts are made to keep patients engaged in the treatment process.

Lawrence A Palinkas, $\mathrm{PhD}$ University of California, San Diego La Jolla, California, USA

1 Geller A. In: Lowinson JH, Ruiz P, Millman RB, editors. Substance abuse: a comprehensive textbook. Second edition. Baltimore: Williams \& book. Second

2 McLellan AT, Arndt IO, Metzger DS, et al. JAMA 1993;269:1953-9. 